\title{
O RETRATO DA DÉCADA DE 1950 PELAS FOLHAS DO JORNAL “TRIBUNA DOS MUNICÍPIOS” DE IRATI (PR)
}

\author{
Claudia Maria Petchak Zanlorenzi \\ aecmari@gmail.com \\ HISTEDBR dos Campos Gerais - PR
}

\author{
Maria Isabel Moura Nascimento \\ Universidade Estadual de Ponta Grossa- PR - UEPG \\ HISTEDBR dos Campos Gerais -PR
}

\begin{abstract}
RESUMO:
O presente texto retrata, especificamente, a década de 1950, tendo por objetivo demonstrar o movimento da sociedade pelo viés de um jornal local, Tribuna dos Municípios, veiculado em Irati (PR). Esse estudo é resultado de uma pesquisa realizada no Programa de Mestrado em Educação da Universidade Estadual de Ponta Grossa, com o título "Educação e Ideologia na Imprensa de Irati- PR (1954-1959)", no ano de 2006.
\end{abstract}

Palavras - chave: Imprensa, Estado, década de 1950.

\section{THE PORTRAIT OF DECADE OF 1950 BY JOURNAL “TRIBUNA DOS MUNICÍPIOS” OF IRATI (PR)}

\begin{abstract}
:
The present text will show, specifically, the decade of 1950, having as objective to demonstrate the society movement by the words of a local newspaper, Tribuna dos Municípios, from Irati (PR).This study resulted from a research developed in the Education Master Degree Program at the State University of Ponta Grosa, with the title "Education and Idelogy at the Press in Irati-PR( 1954-1959), during 2006.
\end{abstract}

Key-words: Press, State,1950 decade.

\section{INTRODUÇÃO}

A imprensa, como objeto de pesquisa, é uma rica fonte para analisar e estabelecer as relações por meio dos discursos que eram veiculados e o seu uso vem consolidando-se de maneira crescente ${ }^{i}$ nas pesquisas acadêmicas.

O presente artigo é parte integrante de uma pesquisa realizada no Programa de Mestrado em Educação da Universidade Estadual de Ponta Grossa, com o título "Educação e Ideologia na Imprensa de Irati- PR (1954-1959), no ano de 2006, que teve por finalidade analisar a educação na década de 1950, pelas folhas do Jornal Tribuna dos Municípiosii , veiculado em Irati (PR).

O procedimento metodológico adotado na pesquisa foi, inicialmente, a coleta e classificação de reportagens no jornal "Tribuna dos Municípios" que tiveram a educação Revista HISTEDBR On-line, Campinas, n.34, p.108-126, jun.2009 - ISSN: 1676-2584 108 
como eixo central, sendo que esse periódico faz parte do acervo da Casa da Cultura de Irati (PR). As notícias levantadas foram copiadas na íntegra das reportagens, digitalizadas e organizadas em um banco de dados específico, agrupadas por temas para depois serem analisadas.

Para esse texto, especificamente, privilegiaremos o movimento da sociedade pelo viés desse jornal local, a "Tribuna do Municípios". Para tanto, optou-se, mesmo correndo o risco de abordar em uma breve exposição, organizar o presente texto em três partes:

* primeiramente, será feita uma descrição sobre a década de 1950, utilizando-se de notícias retirados do referido jornal;

* no segundo momento, serão verificadas as consequiências do posicionamento do Estado e as críticas feitas no jornal, inclusive atentando a sociedade para o descaso que provinha do capitalismo;

* no terceiro momento será analisada ideologia dominante nos meios intelectuais e por fim será discorrido sobre essa e as instituições da época.

É importante salientar que esse estudo inicial foi imprescindível para a posterior análise da educação, pela via do jornal, na década de 1950, haja vista que a partir dessa compreensão foi possível verificar as contradições e relações com os aspectos sociais, culturais, políticos e ideológicos.

\section{O RETRATO DA DÉCADA DE 1950}

O desenvolvimento do capitalismo e do Estado burguês, que influenciaram a imprensa e demais instituições do Estado, aconteceu de forma diferenciada no Brasil, pois este se estruturava no país quando já era dominante em escala mundial, o que significa sua submissão e a reprodução ampliada do capital no nível internacional.

Nos países em que o capitalismo é ainda fracamente desenvolvido - os países que se encontram na fase de transição capitalista, os países em vias de industrialização ou em vias de desenvolvimento (capitalista) - o desenvolvimento do capitalismo apresenta contradições particulares devidas à posição subordinada que eles ocupam no seio da economia mundial. (SILVA, 1976, p. 25)

Esse desenvolvimento no país se deu de forma acentuada, criando um movimento próprio, tendo como característica a dependência do capital estrangeiro, primeiramente da Inglaterra com a produção cafeeira para, depois, principalmente após a II Guerra Mundial, dos Estados Unidos.

Com o final da II Guerra Mundial, que colocou em ascensão as duas superpotências - os Estados Unidos e a ex - União Soviética - e principalmente sob a influência do capitalismo, era necessário que a industrialização fosse incrementada e articulada. É após este período que o país ingressa efetivamente na fase de industrialização, que, até então, se resumia nas indústrias leves, viáveis, com produção em escalas modestas e que, portanto, podiam ser capitalizadas por meio de acumulação dos próprios lucros. (SINGER, 2001, p. 107)

No Brasil, a indústria, desde o seu $1^{\circ}$ surto na década de 1880 a 1890 , desenvolveuse de forma desigual nas diferentes regiões do país, concentrando-se primeiramente nas 
regiões cafeeiras. Assim sendo, é no Rio de Janeiro e em São Paulo que se dá a indústria nascente.

As transformações por quais passou o Brasil, nessa década, entre elas a abolição da escravatura e a imigração, levam a economia cafeeira à rápida acumulação de capital baseada no trabalho assalariado, e é com essa acumulação de capital que nasce a indústria no Brasil, que inicialmente se concentra nos setores de bens de consumo ${ }^{\text {iii }}$.

O complexo econômico gerado pelo núcleo cafeeiro, onde se incluíam desde as estradas de ferro aos bancos, o grande comércio de exportação e importação, assim como a própria mecanização crescente da produção, havia constituído a base de um crescimento industrial tímido e descontínuo, verificado desde o nascimento da "sociedade do café". Germinava, assim, o processo brasileiro de industrialização, favorecido pela ruptura que a expansão cafeeira representara em relação as formas tradicionais de dominação e de reprodução do capital no Brasil. (XAVIER, 1990, p. 31)

Já na década de 50, a industrialização concentrou-se no outro ramo, nos bens de produção.

Pressionadas pelo imperialismo, as classes dominantes nacionais desenvolvimentistas, mas não nacionalistas, clientes históricas do capitalismo internacional, redirecionaram a estratégia de expansão industrial para o setor de produção de bens duráveis, como convinha externamente e pressionava a demanda insatisfeita, internamente. (XAVIER, 1990, p. 44)

Urgia então, aumentar a produção em massa de bens que dependiam da tecnologia e de capitais e que se apoiavam na substituição dos modelos estrangeiros.

[...] no final do século XIX em diante, e acentuadamente a partir dos anos 50, o grande fascínio, o modelo a ser copiado passa a ser mais o American way of life. Fascínio, primeiro do empresariado e da classe média alta, que depois, foi se espairando para baixo, por força do cinema e da exibição, nas cidades, aos olhos dos "inferiores", do consumo moderno dos "superiores", dos ricos e privilegiados. (MELLO; NOVAIS, 1998, p. 605)

O Brasil, então, passa por transformações e por um crescimento que vinha se encaminhando desde 1930. Esse crescimento econômico apoiou-se na intervenção do Estado burguês e patrimonialista ${ }^{\text {iv }}$ que, fazendo valer os interesses da classe dominante, proporcionou investimento em infra-estrutura e em setores importantes da economia transferindo, conseqüentemente, para superestrutura jurídica-política a crença de que a modernização levaria o país ao rol do "Primeiro Mundo", superando, assim, o Brasil periférico e arcaico. Para tanto, as palavras de ordem vestidas à americana, nessa década, eram urbanização, industrialização e tecnologia.

Entre 1945 e 1964, vivemos momentos decisivos do processo de industrialização, com a instalação de setores tecnologicamente mais avançados, que exigiam investimentos de grande porte; as migrações 
internas e a urbanização ganham um ritmo acelerado. (MELLO; NOVAIS, 1998, p. 565)

\title{
AS CONSEQÜENCIAS DO POSICIONAMENTO DO ESTADO REVELADO PELO JORNAL
}

As conseqüências do posicionamento do Estado podem ser vistas na denúncia revelada pelo jornal, que mesmo sem fazer uma crítica mais profunda, analisando a continuidade do pensamento liberal e a ilusão de que triunfam os melhores e os mais trabalhadores, demonstra a situação em que se encontrava o país.

O Brasil, nos últimos tempos, vem sendo dirigido aos trancos e barrancos. Experimentou uma quartelada em 1930 que nada resultou de benefício para a História do Brasil, ou para o Povo Brasileiro, porquanto os homens que assumiram o poder, até hoje proprietários deste país praticamente nada realizaram de positivo para a grandeza da nacionalidade. Os homens de 30 impuseram ao Brasil um estado totalitário cujos resultados até hoje podem ser contatados em todos os setores da vida nacional. (Tribuna dos Municípios, 24-05-1954)

O jornal também caracteriza a forma como se encontrava a sociedade na época, diante os desmandos do Estado e sob a influência do capitalismo, refletida na burocracia e nas instituições. Pontua a alienação do povo e sua falta de preparo moral como causas de tal situação, entretanto ao mesmo tempo que alerta essas manifestações, relaciona apenas ao aproveitamento da situação pelo comunismo.

\begin{abstract}
Abulia intelectual, desmandos administrativos, exploração dos poderes públicos visando interesses particulares, uma "deseducação" progressiva e alarmante das novas gerações, o rebaixamento vergonhoso da moral pública e particular, o abandono dos campos, a macrofalia das grandes cidades, uma agricultura impotente, o domínio dos medíocres, uma indústria alimentada com o sangue do homem do povo, o desvirtuamento os cargos de responsabilidade, o reinado da demagogia, o império da violência encastelada nos poderes públicos, e, sobretudo, o preparo moral, psicológico, econômico, financeiro, de um povo desiludido para o domínio do comunismo. (Tribuna dos Municípios, 24-05-1954)
\end{abstract}

A preocupação com os aspectos citados, conseqüência do posicionamento do Estado, demonstrado pelo jornal nas contradições do contexto, denunciam o receio à infiltração das idéias comunistas, visto que a desilusão poderia ser propícia a estas idéias. Esses eram assuntos que estavam sendo discutidos com o fim da II Guerra Mundial e que evidenciavam disputas ideológicas divergentes dentro da política econômica mundial, com a ascensão da democracia liberal com os EUA e o socialismo tendo à frente a União Soviética, a chamada de Guerra Fria ${ }^{\mathrm{vi}}$.

Entretanto, o texto não amplia a sua análise, observando as contradições das relações sociais capitalistas que se apóiam no progresso das forças produtivas. Ao mesmo tempo em que denuncia as conseqüências do capitalismo, apenas enaltece o receio ao comunismo. 
A sombra do comunismo era um dos maiores receios para a sociedade da época. A forma como este foi divulgado na mídia veio a influenciar opiniões de desprezo e receio a este movimento, como se observa na reprodução feita pelo jornal, do semanário carioca "A Marcha":

E a Rússia é o grande perigo que a todos nós ameaça. Vocês americanos nos levam a carteira, mas deixam-nos nossa vida e nossa liberdade pelo menos política. Mas a Rússia quer levar-nos a liberdade, vida, a dignidade, a honra, tudo o que há de essencial ao ser humano, para que possa dizer que é ser humano. Nesse caso, se vocês ambos sabem fazer a bomba atômica preferimos (embora sejamos contra tamanha barbaridade), vender nosso tório a vocês, para que nos livrem da Rússia, que é o pior bandido da história da humanidade..(Tribuna dos Municípios, 21-07-1955)

Evidenciam-se, nesse texto, os interesses econômicos dos americanos e a forma dissimulada como conseguem os seus objetivos, porém ter a liberdade, pelo menos política, que estes proporcionavam, em comparação ao domínio do comunismo, é menos perigoso e mais vantajoso. Liberdade essa sob a influência do capital e determinada pelas relações de produção. Ao mesmo tempo em que relata os aspectos negativos do mercado americano, incentiva a continuidade e manutenção do consumismo, utilizando-se dos mesmos meios de persuasão ao solicitar que fortaleçam o mercado no país.

Mas não basta que concedamos o nosso tório a vocês e o neguemos à Rússia. É preciso que vocês nos paguem bem. Não pensem que estamos fazendo chantagem. O interesse é de vocês mesmos. [...]. Se somos nós, brasileiros dignos e honrados, não vendendo tório à Rússia, sejam vocês também dignos e honrados, não só pagando bem o tório que lhe vendemos, mas ainda nos ajudando a fortalecer-nos econômicamente, para sermos fortes na hora em que vocês precisam de nós. Assim diríamos se tivéssemos vergonha na cara. Como não temos, olhamos em torno e só topamos com russófilos traidores e com falsos americanófilos, que só querem mancomunicar-se com os americanos para sem nenhum sentimento espoliar os brasileiros, de solidariedade continental, mas como único objetivo de enriquecer-se à custa da nossa miséria.(Tribuna dos Municípios, 21-07-1955)

O jornal já ao reproduzir essa reportagem do outro periódico "A Marcha”, reforça a crítica aos meios utilizados pelo mercado americano, demonstrando a dependência desse em relação ao mercado brasileiro. Todavia também coloca seu posicionamento em favor da manutenção e a própria dependência do mercado brasileiro.

Após a II Guerra Mundial, consolidou-se a influência do imperialismo americano e a concentração de investimentos pelos EUA aos países em processo de industrialização, pois a pressão imperialista

[...] só se fez com mais vigor no Brasil dos anos 50 em função do início da segunda fase da exportação norte-americana de capitais, quando a hegemonia desses capitais no mercado internacional inaugurou a era dos investimentos diretos, contra os investimentos "em carteira", que caracterizavam os capitais europeus. Numa primeira fase, que durou aproximadamente até 1953 , a penetração do capital norte-americano na

Revista HISTEDBR On-line, Campinas, n.34, p.108-126, jun.2009 - ISSN: 1676-2584 112 
América Latina foi moderada, uma vez que a Europa, que se reconstruía, absorvia a maior parte da ajuda norte-americana. Após 1955, quando terminou a reconstrução européia, a penetração do capital norteamericano voltou-se maciçamente para os países latinos americanos que encetavam o seu processo de industrialização, entre eles o Brasil. (XAVIER, 1990, p. 44)

Mesmo com toda a dominação capitalista dos EUA, o jornal anuncia que é melhor ficar sob a tutela do capitalismo, do que a dominação comunista, sem verificar que aquele também, de modo desmascarado, domina autoritariamente - utilizando-se da ideologia de desenvolvimento e modernidade - as regras da economia mundial. Através de publicações e do cinema, disseminou-se a propaganda negativa do comunismo e em contrapartida enaltecia-se o modo de vida norte-americano e os valores capitalistas, nos quais "[...] o postulado de que cada indivíduo é capaz de ação racional, de calcular vantagens e desvantagens ajustadas à realização de seus interesses materiais ou de seus desejos, isto é, o hommo economicus utilitário."(MELLO; NOVAIS,1998, p. 565, com grifos do original)

Essa influência é retratada com bastante freqüência no jornal, que mesmo se colocando abertamente contra o comunismo também demonstra sua opinião sobre o imperalismo norte-americano, no artigo "Juventude Transviada".

Depois que o Brasil gastou divisas para importar um filme estrangeiro com esse título, recebeu a geração "coca-cola", uma nova denominação: juventude transviada. [...] $\mathrm{O}$ adjetivo maldito é acrescentado impiedosamente por todos. Juventude transviada... Com o coração confrangido perguntamos angustiosamente: - Quem transviou, a juventude? (Tribuna dos Municípios, 01-08-1958)

Observa-se na crítica ferrenha do periódico, o pensamento conservador, contrário ao modernismo e liberalismo que vinha com a influência americana, fazendo alusão ao termo "juventude transviada", ou seja, que se desviou do seu caminho, ou do seu dever, que seria dos bons costumes.

Ao enaltecer a moral e a religião, revela que a ideologia que vinculava em suas folhas, enfim o ocultamento da realidade social, estava vinculada ao pensamento idealista de Hegel de que a religião e a filosofia tem o mesmo conteúdo e seriam a solução aos problemas da realidade social.

Hegel interpreta a história como progresso na consciência da liberdade. As formas de organização social correspondem à consciência da liberdade e, portanto, a consciência determina o ser. A consciência de uma época histórica e de um povo se expressa sobretudo na religião, que é onde o povo define por si mesmo o que considera como verdade. (BOTTOMORE, 2001, p. 176)

Ao criticar o predomínio do cinema americano e as revistas em quadrinhos, nas atitudes da juventude brasileira da época, transfere uma parcela de culpa desta influência no ensino do país e seus dirigentes e na falta de civismo.

Vários são os responsáveis por esta situação. Os dirigentes do ensino no Brasil têm grande parcela de responsabilidade. O exemplo da juventude 
transviada nos vem da América do Norte, atravez o cinema e as revistas foto cine. (Tribuna dos Municípios, 01-08-1958)

Compara tal situação como conseqüência do distanciamento da moral e da religião, demonstrando o pensamento ideológico conservador em relação à ênfase que estava sendo dada ao progresso rápido, o luxo, a ânsia pelo dinheiro em detrimento aos princípios religiosos. Porém, mesmo sem analisar a apologia indireta ao consumismo e consequientemente aos princípios do capitalismo e sua universalidade, responsabiliza os grandes pedagogos e dirigentes do país.

Os chamados grandes pedagogos brasileiros atravez do I.N.E.P. anarquisaram com o ensino em nossa Pátria. A sua inspiração é a de Dewey, também considerado grande pedagogo norte americano e acusado agora por "Life" e pelo "Time", como o materialisador do ensino público nos Estados Unidos e como resultados, "a anarquia e fraqueza notável nos estudos, a delinquiência juvenil, ameaçadora da ordem geral e uma inferiorização muito grande, na formação das gerações atuais. (Tribuna dos Municípios, 01-08-1958)

Nessa época, as propostas educacionais, com a influência do grupo de renovadores, eram fundamentadas pelas idéias de John Dewey sob a égide da modernidade, a adaptação do indivíduo na sociedade, a formação cultural das gerações, enfim os preceitos liberais.

Observa-se que o jornal, ou seja, classe à frente deste, denuncia a influência dos americanismos que vinha se consolidando como modelo de vida e estilo em todos os meios de comunicação.

O imperialismo - demonstrado nas notícias do jornal sem uma análise mais aprofundada - através do cinema e os meios de comunicação em massa, exerceu papel de destaque na mudança dos valores, no nível de consumo e modos de agir dos jovens que a estes tinham acesso. Entretanto a desigualdade social era grande e a maior parte da população do país continuava à margem, vítima da dominação do capitalismo, como se verifica no seguinte texto do jornal sobre a vida da população.

A vida do pobre Brasil está se tornando pesadíssimo fardo. $\mathrm{O}$ aumento do preço dos gêneros de primeira necessidade eleva-se, dia a dia, em proporções tais que não é mais possível estabelecer-se um orçamento doméstico capaz de funcionar no curso de três ou quatro meses. $\mathrm{O}$ cruzeiro, nosso dinheiro, cada vez mais se desvalorizando. Nestas condições, o operário e o homem de classe média vêm sendo iludidos com aumentos de salários paralelamente seguidos de tais aumentos da comida, da roupa e do aluguel de casa, que de nada adianta ganhar mais. Quer dizer que tudo está errado neste país. (Tribuna dos Municípios, 2201-1955)

A meta, nessa década, era a industrialização acelerada, enquanto que outros setores, entre eles o setor agrário, ficavam debilitados. Comprova-se, neste texto, como a política econômica vinha sendo comandada pelo Estado, mantendo o círculo vicioso entre o salário, a produção, o consumo e as desvalorizações com o aumento dos produtos, o que agravava cada vez mais as contradições entre as classes. Perpetuava-se a continuidade dos princípios liberais de consumismo, excedente e elitização. 
O que barateia o custo de vida é o aumento de produção. Mas como aumentar a produção, se não temos transporte, não temos assistência financeira para o agricultor, não temos assistência técnica, não temos mecanização na lavoura? As restrições de crédito aos que trabalham no Brasil, principalmente aos pequenos, aos modestos lavradores, industriais e comerciantes, longe de construir medida saneadora de nossas finanças é um processo de diminuição das safras e dos produtos indispensáveis à vida comum do povo brasileiro. O problema do operário está intimamente vinculado a todos os demais problemas da vitalidade nacional. [...] Mas, nesse andar das coisas, para onde vamos? É chegado o momento de pormos um paradeiro nesse rumo catastrófico. (Tribuna dos Municípios, 22-01-1955)

\section{O JORNAL E A IDEOLOGIA DOMINANTE NOS MEIOS INTELECTUAIS}

O jornal retrata a ideologia dominante nos meios intelectuais do país, identificando como figura principal dessa ideologia o desenvolvimento capitalista, através do descaso com a economia rural em virtude do processo da industrialização. Almejava-se que o país entrasse no rol dos países desenvolvidos, apoiado nos princípios liberais, todavia a política econômica assumida traça os rumos para tal desenvolvimento sem verificar a verdadeira realidade brasileira que até então era subordinada à oligarquia agroexportadora. A economia rural sempre foi importante, porém, neste contexto, não é mais, e Skidmore concebe tal fato como conseqüência de interesses eleitorais ao dizer que:

A Constituição de 1946 proibia os analfabetos de votar; e, já que as zonas rurais eram esmagadoramente analfabetas especialmente nas regiões mais retrógradas, os desprotegidos rurais não tinham peso no processo político. Nenhuma figura política de importância, em 1950, propôs quaisquer mudanças radicais no sistema de propriedade rural. A economia rural não tinha importância em 1950. (SKIDMORE, 1969, p. 116)

Porém, a população rural tinha grande proporção no país. Em Irati, como exemplo, da população recenseada na década de 50, 69\% estavam localizados na zona rural ( IBGE, 1959, p. 258). O descaso com o setor rural ocasiona o movimento migratório no país, onde esta população sai em busca de uma vida melhor. "Nas atividades urbanas, contudo o trabalho assalariado assumia predominantemente a forma capitalista em troca de uma jornada definida, o trabalhador era renumerado em dinheiro.”(SINGER, 2001, p. 98)

Deixando a lavoura rumo à cidade, na ânsia de melhores oportunidades e progresso individual, princípio do capitalismo, o trabalhador rural aumenta o processo de urbanização, característico desta década. "Foi assim que migraram para as cidades, nos anos 50, oito milhões de pessoas (cerca de $24 \%$ da população rural do Brasil em 1950.'(MELLO; NOVAIS, 1998, p. 565) As causas deste descaso aparecem no relato do jornal que descreve a realidade dos moradores da zona urbana:

Dentro de um pouco, teremos novos níveis salariais. Tivemos já, aumento de vencimentos aos funcionários públicos. Isto tudo significa elevação geométrica dos preços das utilidades, êxodo absolutamente dos campos e a inundação das cidades por novos milhares de bocas para comer. Que já se fez, ou que está fazendo pela lavoura, pelo homem do sertão? Podemos dizer nada. Os órgãos responsáveis pela produção, não se entendem. $\mathrm{O}$ sertão não têm conforto. Não tem médico, não tem farmácia. As escolas

Revista HISTEDBR On-line, Campinas, n.34, p.108-126, jun.2009 - ISSN: 1676-2584 115 
de modo geral, não têm professor à altura da alta e dignificante missão de ensinar às crianças rurais. A vida do lavrador é, atualmente, a pior possível [...]. (Tribuna dos Municípios, 29-06-1956)

Ao contrário do interior do país, nos grandes centros, a instalação da indústria e, conseqüentemente, as relações capitalistas tomavam outra dimensão, pois atendendo aos interesses da classe dominante empresarial, não se caracteriza mais pela indústria leve e de consumo, e sim pela ênfase na produção de equipamentos, bens de consumo duráveis e produtos químicos, o que, conseqüentemente, requeria capitais mais elevados. (RIBEIRO, 1982, p. 140) Para tanto, era preciso a adoção de políticas mais sistemáticas e o capital estrangeiro era visto como promotor do desenvolvimento econômico, mais especificamente o capital norte - americano.

Diante desse contexto, embates ideológicos na política econômica, em relação a que posição o Estado deveria tomar, influenciaram o rumo do país. Três grupos destacavam-se: neoliberal, desenvolvimentista-nacionalista e nacionalista radical $^{\text {vii }}$.

A ala neoliberal baseava-se em princípios ortodoxos, em que as medidas fiscais e monetárias, bem como a política de comércio exterior, deveriam seguir os princípios estabelecidos pelos teóricos e praticantes da política do banco central dos países industrializados.

O grupo dos desenvolvimentista-nacionalistas defendia a industrialização, mas argumentavam que as forças espontâneas que haviam conseguido a industrialização, no Atlântico Norte, seriam inadequadas no Brasil. Visavam a uma economia mista, na qual o setor privado receberia novos incentivos na proporção de um determinado número de prioridade de investimentos, ao mesmo tempo em que o Estado interveria mais diretamente, através das empresas estatais e das empresas de economia mista.

Este grupo também compreendia que o capital estrangeiro poderia desempenhar um papel importante ao contrário das idéias do grupo nacionalista radical que atribuíam o subdesenvolvimento brasileiro a uma aliança natural de investidores particulares e governos capitalistas dentro do mundo industrializado, o que limitava o Brasil em um papel subordinado. Sua única linguagem aos empreendimentos econômicos era o controle completo estatal.

A corrente nacionalista cresceu com o final da Segunda Guerra Mundial e na América do Sul e Central esta assumiu notações de oposição ao predomínio econômico dos Estados Unidos.

Nessa década, tanto os governos de Getúlio Vargas, Café Filho como Jucelino Kubitschek, utilizar-se-iam de uma economia baseada na ideologia nacionalismo desenvolvimentista, dado que a influência do capitalismo já estava bem concretizada no país e sem os investimentos de capitais estrangeiros não haveria possibilidade de modernizá-lo.

O presidente Getúlio Vargas, eleito em 3 de outubro de 1950, teria em suas mãos um governo bem diferente daquele que já havia administrado autoritariamente entre 1930 a 1945. No início, promoveu várias medidas destinadas a incentivar o desenvolvimento econômico com ênfase na industrialização, mas, ao mesmo tempo, via-se diante de problemas que estavam causando transtornos e repercussões sociais, entre elas o avanço da inflação e a crise econômica do país,

Gritam os homens públicos improvisados: Estamos de mal a pior. É necessário abrir estradas para escoar os produtos. Outros afirmam: É preciso promover a deflação. Dizem alguns: A solução está na reforma da 
Constituição. E outros ainda argumentam: o que nos cumpre fazer é resolver o problema da produção, só produzindo mais, abaixará o custo de vida. Ora, não poderemos pretender coisa alguma, se olhamos apenas para uma face do problema. E como é doloroso observar panoramas assim... A ambição o homem que só pensa na matéria, que só vive da matéria, que se escravisa à matéria. Não encontramos mais o ideal DE SER ALGUMA COISA NA VIDA, mas os desejo desenfreado de TER ALGUMA COISA NESTE MUNDO, cuja existência do homem é tão efêmera. (Tribuna dos Municípios, 18-09-54)

A crítica feita à situação em que se encontrava a sociedade e o Estado reflete de forma enfática a opinião contrária aos preceitos do liberalismo, entre eles o individualismo e a competição no mercado. Utilizando-se de termos como "materialismo", retrata que os vários problemas que afligem o país não devem ser analisados e solucionados de forma parcial, mas que fazem parte de um problema único, a ambição e o poder, ou melhor, os preceitos do capitalismo, entre eles a reprodução das relações de produção.

Todavia, dessa crítica direcionada ao modo como estava a sociedade, coloca como solução outra forma ideológica, também com princípios que enalteciam o poder e a dominação, muito presentes nessa época, no tocante a moral individual e familiar.

Assim pensando e assim agindo, o homem moderno se afastou Daquele que é Luz e que é Vida, do Princípio e Fim de todas as Coisas É por isso que se rouba, sem medo. Que se mata por nada, ou quase nada. Que as funções não são desempenhadas com interesse de bem servir. Que as profissões não são mais exercidas com o carinho que caracterizaram os grandes empreendedores. É por isso que o mundo moderno vive angustiado, desesperado, torturando o homem tem todo o conforto, mas que sente a desgraça da ambição de querer o que nem mesmo ele sabe o que seja a desgraça da satisfação insatisfeita. É verdade que a produção está desorientada, que não temos transporte, que a nossa moeda é inflacionária, que vivemos na desorganização. Mas é preciso resolver um problema apenas para que se possa chegar a solução completa. E o problema é apenas moral e religioso e urgente, renovar o homem. O problema é apenas moral e religioso. (Tribuna dos Municípios, 18-09-54)

É essa orientação que continuará guiando a igreja brasileira, agência poderosa de moralização da sociedade, ainda que já penetrada pelo individualismo (MELLO; NOVAIS, 1998, p. 610). A igreja, mesmo ao romper com o Estado a partir da República, ainda exercia grande força ideológica e família teria um papel preponderante nesta continuidade.

Retorno a Cristo é a caminhada que devemos empreender. Embuido do espírito cristão verdadeiro, formando na escola do sacrifício e da dignidade, haveremos de empreender aquela caminhada e resolver todos os problemas do Brasil, reformando o homem, preparando a juventude para assumir as tremendas responsabilidades de nos governar amanhã. (Tribuna dos Municípios, 18-09-54)

O posicionamento do jornal também é ideológico e dogmático, pois para este a renovação do homem, a partir dos princípios religiosos, poderia sanar e acabar com os problemas sociais. Entretanto, este pensamento conservador, utilizando-se da mesma estratégia de alienação, não possibilita a compreensão que a situação político-econômica 
do país estava desencadeando conseqüências, entre elas, contradições políticas internas, dado a forma como o Estado posicionava-se a partir da dependência dos investimentos do capital estrangeiro.

É diante destas contradições e das restrições políticas internas que Vargas, para amortecer os efeitos de sua política econômica, adota uma linha nacionalista de investimento, com a aprovação de leis que causariam um grande impacto junto à sociedade como, por exemplo, o Projeto Petrobrás.

O presidente não tinha, com este projeto, a intenção do monopólio estatal e sim uma empresa mista, sob o controle majoritário da União, com ações abertas ao capital estrangeiro. Conseqüentemente, os ânimos dos nacionalistas foram alterados, pois eram favoráveis à participação do setor privado nacional na exploração do petróleo.

Diante disso, a União Nacional dos Estudantes, inicia uma campanha visando a mobilizar a opinião pública com o lema "O petróleo é nosso". Em três de outubro de 1953, Vargas sanciona uma lei criando a Petrobrás, como empresa de propriedade e controle totalmente nacionais, com participação majoritária da União, que detinha o monopólio de todas as etapas da indústria petrolífera, menos a da distribuição de produtos. (RODRIGUES, 1992, p. 49). O jornal Tribuna dos Municípios, em relação a esse tema tem a seguinte opinião demonstrada no texto abaixo sob o título "Bancando o tatu":

O País foi abalado há tempo com a insistente campanha do "Petróleo é nosso". Os demagogos de sempre, aproveitaram a "deixa" e entraram no barulho valendo, pregando um nacionalismo vesgo e pernicioso. $\mathrm{O}$ "Petróleo é nosso". Ninguém poderá perfurar nossos poços, em busca do precioso combustível. Está claro! O que é difícil, complicado, arriscado, problemático, deve ficar conosco. Quando chega a hora de ganhar dinheiro, vamos entregar aos estrangeiros. É isso o que desejam os falsos nacionalistas. Segundo imprensa, a Petrobraz, acaba de assinar contrato com a Esso e está em negociações, com a Shell, para exportar petróleo, que será refinado na Venezuela. Depois, já se sabe, compramos o mesmo petróleo nosso, com a diferença de ficar mais caro, é evidente. Que papel estamos, então fazendo nesta história de petróleo, cujo preço sobe assustadoramente, quase todas as semanas, encarecendo cada vez mais o custo de vida?. (Tribuna dos Municípios, 14-03-1959)

Deixar a condição de colônia e submissão, peculiar dos países periféricos, era o pano de fundo da campanha que envolvia o petróleo brasileiro e a própria atitude do Estado em relação a sua política de intervenção. O jornal manifesta de forma enfática a exploração desta situação, na qual envolvia empresas americanas:

Fazemos o trabalho pesado grosseiro, perigoso e extremamente dispendioso, furando aqui e acolá, na maioria das vezes sem resultado, como foi o caso de Male, nosso município visinho. Depois de longos gastos e naturais desperdícios, foram embora, sem dar a mínima notícia, alentadora sobre a existência do que procuravam. O mais rendoso, mais fácil, deixamos para o estrangeiro, que intimamente, deve aplaudir nossa atitude. Fornecemos com facilidade, aquilo que lhe é difícil encontrar. Evidentemente, estamos bancando é o tatu. Só furamos a terra. O ganho maior é de outros. (Tribuna dos Municípios, 14-03-1959) 
O texto critica a "insistente" campanha "O Petróleo é nosso", dado que ninguém poderia usufruir o que está no território brasileiro, o que já estava claro tornando-se até redundante. Indo além, concentra suas críticas nos abusos das companhias americanas, bem como o rumo que a empresa Petrobrás poderia tomar em relação ao seu capital. Ao mesmo tempo em que denuncia tal situação, não deixava de manifestar indiretamente a sua opinião ideológica contra o comunismo, em virtude que a tal campanha nacionalista tinha o apoio do Partido Comunista. As críticas, como se pode observar ultrapassava o campo econômico.

Diante desse contexto, pouco a pouco, Vargas perdia o apoio dos setores dominantes com medidas que evidenciavam sua simpatia aos trabalhadores, por exemplo, o aumento do salário mínimo e a acusação de ser conivente aos nacionalistas, taxados de agitadores.

A imprensa, em quase sua maioria antigetulista, foi enfática em suas críticas contra o presidente acusado pela crise econômica do país e a corrupção. "O povo brasileiro sofre a mais tremenda das crises. Crise financeira. Crise moral. Crise de vergonha. Crise de homens públicos no poder.'(Tribuna dos municípios, 13-06-1954)

Os jornais, de um modo geral, tiveram um papel importante nesse momento delicado da política e a influência de suas opiniões sobre o governo, que ora se colocava dentro dos preceitos capitalistas ora enaltecia o nacionalismo, tiveram grandes repercussões que contribuíram para o desfecho da Era Vargas. Apesar das críticas que se colocavam até então para o governo de Getúlio Vargas, este sai de cenário nacional como grande estadista, ocasionando repercussões negativas em todo o país.

Com a morte de Getúlio Vargas, seu vice, Café Filho, assume a presidência "E a história em mais de um de seus caprichosos acasos, registrou mais um fato pitoresco: João Café Filho, aquele modesto jornalista, e apenas jornalista, nada mais, ascendeu à Presidência da República."(Tribuna dos Municípios, 14-05-1955)

Considerado como um período transitório, o governo de Café Filho, realizou uma medida que marcaria efetivamente o capitalismo no Brasil, a aprovação da Instrução $113^{\text {viii }}$ da SUMOC (Superintendência da Moeda e do Crédito). Através desta instrução

[...] reconhecia-se às empresas estrangeiras, interessadas em operar no Brasil, a concessão de favores cambiais para transferir, de seus países de origem, maquinarias industriais depreciadas, como se fossem equipamentos novos, embora já funcionando aqui indústrias nacionais similares. (RAMOS, In. RIBEIRO, 1982, p. 140)

Já o presidente Jucelino Kubitschek, eleito em 03 de outubro de 1955, teve seu governo embalado por uma extraordinária expansão da produção industrial e altos índices de crescimento. O jornal satiriza o banquete da posse do novo presidente que deixaria a marca de otimismo e a imagem de "Anos Dourados".

Para conhecimento de nossos leitores, principalmente daquelas centenas de leitores da zona rural, onde não lhes chegam às mãos, jornais da capital, divulgamos o "menu" do banquete de posse do snr,Jucelino Kubistchek. Não ficaria melhor um "churrasco" à gaúcha? Cremos que sim, entetanto ... eis o "menu" transcrito de "O Jornal" do Rio: Caviar Frais d'Astrachan; Consomó Madriléne em geles; Paillettes au Parmesan; Homard à l'Americaine; Riz Pilaw; Faisan Roti aux mignons de FoieGras; Salde Vougue; Parfait aux Pommes em Corbeille [...].( Tribuna dos Municípios, 11-02-1956) 
O período "áureo do desenvolvimento econômico brasileiro" como é chamado, seguiu a política nacionalista desenvolvimentista, prometendo, com seu famoso Plano de Metas, "50 anos e 5", o qual

[...] objetivava implantar no Brasil os setores industriais mais avançados, com a indústria elétrica pesada, a química pesada, a nova indústria farmacêutica, a de máquinas e equipamentos sofisticados, a automobilística, a indústria naval, ou levar adiante indústrias estratégicas como a do aço, a do petróleo e a da energia elétrica."(MELLO; NOVAIS, 1998, p. 610)

O Plano continha 31 objetivos para os setores de energia, transporte, alimentação, indústria de base, educação e a construção de Brasília, dando prioridade à indústria automobilística, dado a sua capacidade de atrair capital externo e tecnologia e de gerar um sistema articulado de produção. (SINGER, 2001, p. 107) Em relação à política de Getúlio Vargas, altera a forma de crescimento industrial até então vigente, com a associação de empresas privadas brasileiras com multinacionais e estatais.

O governo JK promoveu uma ampla atividade do Estado tanto no setor de infra-estrutura como no incentivo direto à industrialização. Mas assumiu também abertamente a necessidade de atrair capitais estrangeiros, concedendo-lhes inclusive facilidades. Desse modo a ideologia nacionalista perdia terreno para o desenvolvimentismo. (FAUSTO, 2001, p. 236)

Em seus discursos revelam-se componentes da ideologia desenvolvimentista vinculada diretamente com o populismo. Propondo mudanças e garantindo a ordem, a ideologia desenvolvimentista do Estado tinha como objetivo último o desenvolvimento capitalista do país.

No quadro da industrialização brasileira, desde 1930, o Estado vinha ampliando consideravelmente sua participação na economia, e assumindo o papel de gerente político dos conflitos de classe. Estes aspectos, bastante reforçados no período JK, explicam, em parte, a manutenção da aliança populista até meados dos anos 60 . O desenvolvimentismo é a ideologia que propõe " mudar dentro da ordem para garantir a ordem". Concretamente isto significa mudar dentro do sistema capitalista para garantir o objetivo último que é o desenvolvimento capitalista do Brasil (cf. Cardoso, 1977). Na impossibilidade de obter internamente os recursos necessários para este fim, é legítimo obtê-los nos países do bloco ocidental, a "ordem" maior na qual o Brasil está inserido. Não estranha, portanto, que, ao mesmo tempo, JK defendesse o nacionalismo e abrisse as portas ao capital estrangeiro. (RODRIGUES, 1992, p. 62)

A continuidade da subordinação econômica do país foi sempre reforçada pela cumplicidade da classe dominante, garantido, assim, o poder e, conseqüentemente, seus privilégios. Essa classe ditava os rumos da política nacional, na era JK, utilizando-se da ideologia desenvolvimentista e levava todos acreditarem que era possível o desenvolvimento efetivo do país. 
Para isso, foram utilizadas formas de disseminação ideológica, inclusive a imagem do presidente intitulado presidente "Bossa Nova", cercada de otimismo e confiança.

Ao contrário do que o Estado vinculava, o restante do Brasil ficava aquém das regalias e benefícios, conforme retrata o jornal.

Política de arraial é aquela baseada apenas em mesquinharias. Os célebres "coronéis" dominam a situação, mas não resolvem coisa alguma e se perdem no emaranhado das confabulações e gastam tempo precioso em troca de inspetores de quarteirões e sub delegados. A política de arraial, apesar do progresso das cidades continua existindo, com uma única diferença: os "coronéis" foram substituídos pelos "chefes", pelos "líderes". Os "coronéis" apesar de tudo, tinham grande respeito, a sua barba e os seus bigodes eram a garantia da palavra de homem honrado. Os "chefes", os "líderes", entretanto, não usam mais barba, nem bigode e por isso, a sua palavra voa como o vento, desvia a trajetória como o embriagado nas ruas lamacentas. E isso acontece em toda a parte sem exceção. (Tribuna dos Municípios, 24-03-1956)

Comparando e igualando a situação vigente aos tempos dos coronéis, o jornal demonstra o status quo da sociedade brasileira, enfim, a permanência do poder na mão da oligarquia, aumentando cada vez mais a divisão de classe. Não apenas na economia, como também na política, pois os municípios, vítimas da centralização do Estado, não usufruíam dos impostos, os quais eram destinados aos grandes centros.

A política de arraial domina mesmo, os salões embelezados dos palácios, com poltronas ventiladas e ar refrigerado. E nisso se perdem horas preciosas, dias preciosos que, transformados em ação vigorosa em benefício da Nação, a tornariam a mais forte do universo. Política de arraial é a mesma em toda a parte, com qualquer partido que domine a situação. Enquanto isso, os municípios do interior não têm dinheiro para o seu calçamento para a sua rede de água de esgoto, para as suas estradas, para a sua assistência social, porque, enquanto confabulam e discutem os políticos, o povo paga impostos para embelezamento das capitais ostentadoras de luxo e de extravagâncias abomináveis. (Tribuna dos Municípios, 24-03-1956)

Além do descaso com as cidades do interior, no governo de Jucelino, a inflação e a dívida externa foram aspectos negativos, pois ao aportar recursos para seu plano de metas, o presidente abriu as portas para o crescente endividamento, como também a urbanização ocasionou o favelamento e todas as conseqüências sociais, ambientais e políticas.

Do ponto de vista do crescimento o resultado do Plano de Metas de Jucelino, em curto prazo, foi um sucesso, porém os gastos governamentais para sustentar o programa de industrialização, a construção de Brasília e um sério declínio dos termos de intercâmbio com o exterior resultaram em crescentes déficits do orçamento federal. (FAUSTO, 2001, p. 238)

Os moldes como foi executado o desenvolvimento agravou os desníveis econômicos, políticos, cultural e social. No plano macro econômico caracterizou-se pelo triunfo das multinacionais, no plano político pela tecnocracia, no plano cultural pela "mass comunication" e a repressão e, enfim, no plano social, pela reprodução acelerada da divisão de classe. ( MOTTA, 1980, p. 8) 


\section{A IDEOLOGIA PELAS INSTITUIÇÕES}

Uma das instituições que garantiu a manutenção e a reprodução da ideologia nacionalista-desenvolvimentista foi o ISEB (Instituto Superior de Estudos Brasileiros) no governo de JK. Com esse Instituto, o presidente atraiu intelectuais para lançarem vários livros e publicações, que explicavam as causas e efeitos do subdesenvolvimento, e indiretamente divulgava a ideologia desenvolvimentista.

[...] a linha mestra, claramente anunciada pelo governo, era a industrialização forçada, a todo vapor (os famosos "50 anos em 5"), cercada por uma aura de otimismo e de confiança nas "potencialidades do país e de seu povo", e amparada por um planejamento técnico eficiente. A equipe técnica que assumiu a tarefa, formada basicamente por "novos economistas", constituiu-se num verdadeiro grupo tecnoburocrático que, ao invés de definir uma política econômica fundamentada, preocupou-se exclusivamente em acelerar "eficientemente" a expansão industrial brasileira. A ideologia subjacente a essa prática, e que se explicitaria pós 64, foi escamoteada internamente, através de uma política de compromissos habilmente manipulada, por uma "ideologia particular fascinante", o Nacional Desenvolvimentismo. (XAVIER, 1990, p. 47)

A intelectualidade isebiana estava "[...] empenhada em converter-se em arauto da "consciência nacional. Superar-se-ia o subdesenvolvimento, e se instauraria a sociedade burguesa, a sociedade nacional." (MOTTA, 1980, p. 166)

O ISEB também promoveu cursos para jovens que tocados pelo otimismo multiplicavam a idéia de desenvolvimento do país. No seu Regulamento Geral era clara a ideologia, pois afirmava que tinha por finalidade o estudo, o ensino, e a divulgação das ciências sociais, a fim de realizar uma análise e compreensão crítica da realidade brasileira visando à elaboração de instrumentos teóricos que permitam o incentivo e a promoção do desenvolvimento nacional. (TOLEDO, 1982, p. 42)

O ISEB propunha-se constituir ou lançar bases de um "pensamento brasileiro" (autêntico ou não-alienado) através de um projeto teórico-ideológico de natureza totalizante onde confluíram disciplinas e ciências diversas: sociologia, história, política, economia e filosofia (Idem). Apesar de não admitir que seu trabalho promovesse a ideologia, e sim a produção científica e teórica, o pensamento isebiano procurava legitimar a ideologia nacional desenvolvimentista.

O ISEB foi fundado com o objetivo de elaborar a teoria do desenvolvimento, procurando os seus rumos e definindo os processos que deveriam ser adotados com o objetivo de promovê-lo. Era um instituto de pós-graduação, destinado a pessoas de diversas natureza e bases de formação, que detivessem um mínimo de parcela de poder particularmente, empresários e chefes militares - que, ali, eram introduzidas às questões relativas ao desenvolvimento, de tal e qual a Escola Superior de Guerra faz, no tocante à teoria da segurança nacional. [...] foi durante o governo de Juscelino Kubistschek que o ISEB desenvolveu-se, plenamente.[...] O ISEB, cujos esforços se dirigiam, exatamente, para a elaboração de uma teoria do desenvolvimento, ganhou força, nesse momento. Foi também nesse período que o Instituto cindiuse em duas correntes principais, cujas visões divergiam: um determinado 
grupo entendia o desenvolvimento à base de capitais nacionais; outro defendia maciços ingressos de capital estrangeiro. (SODRÉ, 1999, p.14)

Era um órgão que até 1964, quando foi fechado com o golpe militar, serviu e contribuiu para a manutenção e divulgação das ideologias da época, sob a tutela da classe dominante, dado que era destinado às pessoas que mantinham certa liderança. "Está claro que se o projeto dito 'nacionalista' parte dos aparelhos do Estado burguês, então não há nada a fazer: não é por aí que vai passar a libertação do povo.” (MOTA, 1980, p. 13) Assim como os demais aparatos disseminadores da ideologia nacional-desenvolvimentista, o ISEB organizou propagandas, notícias e publicações teóricas que estivessem de acordo com as idéias dominantes do Estado burguês.

No momento áureo da corrida, pelos fins da década de 50, a integração Brasil - Imperalismo produzia arremedos de resistência, como o nacionalismo desenvolvimentista à ISEB: ideologia conciliante e ineficaz, pois tendia a imitar, a curto prazo, os males que a fizeram nascer, males de gigantismo industrial e burocrático. O alvo era a passagem, ou melhor, o "arranque" salvador graças ao qual teríamos uma infra-estrutura nacional sem passar pelo inconveniente do Estado opressor. (MOTTA, 1980, p. 4)

O Estado e seus aparelhos ideológicos, fundamentado pela lógica de crescimento econômico, deixa para trás questões de alcance social, mesmo utilizando-se do populismo e do discurso ideológico de harmonia entre as classes e bem estar social. "A legitimação do Estado brasileiro, na segunda metade do século XX, fundou-se basicamente na capacidade de gerar crescimento econômico, com descaso pelas dimensões sociais, em particular, a educação e a saúde." (SORJ, 2000, p.20), típico de todo estado burguês que organiza um modo particular a dominação de classe, utilizando-se de condições ideológicas necessárias à reprodução das relações de produção, sem se preocupar com as questões sociais e sim apenas com o crescimento da economia e dos capitais da burguesia. O retrato dessa situação está no fragmento abaixo, editado pelo jornal:

Existe no Brasil, um Ministério da Saúde. Várias secretarias da saúde, nas capitais dos estados. Postos de saúde pontificam em todos os recantos. Uma infinidade de organizações oficiais ou oficializadas, destinadas à defesa da saúde do povo existem por tôda a parte. Apesar de tudo isso, a saúde em nossa terra, é um caso muito sério e nunca esteve o povo tão mal servido como agora. É correr o interior e a verdade nos alta aos olhos, para enchê-los de lágrimas. Abandono. Os médicos são mal pagos e talvez por isso há falta dêles. . (Tribuna dos Municípios, 10 -01-1958)

O burocratismo também é denunciado nesse texto, pois para que se consolide o Estado burguês é necessário um conjunto de recursos materiais e humanos com a finalidade de conservação do processo de extorsão e de conservação da dominação de uma classe por outra. (SAES, 1985, p. 39) Fica evidente também as conseqüências desse burocratismo, quando o texto relata de forma enfática as contradições existentes na sociedade, entre elas a falta de estrutura nas cidades do interior em comparação aos grandes centros e a função dos institutos de previdência. 


\begin{abstract}
Não há ambulâncias nas cidades principais, a começar da nossa. Um doente fica mal em lugares distantes, onde não há estrada, não há telefone, não há telégrafo, e morre antes do tempo. Para consolar a família dizem que era destino. Os institutos de previdência que estão matando o interior com uma arrecadação enorme, constroem prédios nas cidades grandes, em vez de distribuir hospitais pelo Brasil afora. Hospitais com o equipamento necessário a bem entender as populações interioranas. A saúde pública deve ser olhada com carinho pelos nossos homens de govêrno. É preciso que deixem de lado a demagogia que nos desgraça, que abandonem o interêsse pessoal a influir atos políticos e se voltem todos, com o alto e dedonado interêsse de servir realmente ao povo. Dentro dêsse esquema, está, num dos primeiros planos, a saúde dos brasileiros. (Tribuna dos Municípios, 10-01-1958)
\end{abstract}

É também com a educação, outro aparelho ideológico, que é possível observar o poder ideológico do Estado burguês, na década de 1950.

Os textos retirados do jornal e analisados deram suporte para a verificação do posicionamento do Estado e sua influência em um contexto no interior do país e que refletia os interesses nacionais. Tais textos, mesmo de forma indireta e muitas vezes colocando-se em um ideal conservador, dão pistas sobre a manutenção dos ideais capitalistas, típicos desta década em que no país vinculava-se a necessidade de progresso pela industrialização.

\title{
CONSIDERAÇÕES FINAIS
}

Utilizar a imprensa, mais especificamente o jornal, como objeto de pesquisa, possibilitou uma análise concreta do contexto histórico. É importante salientar o papel do pesquisador que se utiliza deste meio e a clareza que deve ter da imprensa como aparelho ideológico do Estado.

Todavia, é uma rica fonte para estabelecer as relações através dos discursos que eram veiculados. Mesmo sendo a Tribuna dos Municípios um jornal de uma cidade do interior do país, foi possível verificar a influência dos movimentos que se colocavam na sociedade e a força da ideologia do capitalismo, o que demonstra a importância de pesquisas que possam analisar todos os contextos do Brasil, não apenas dos grandes centros urbanos.

\section{REFERENCIAS}

BOTTMORE, T. Dicionário do pensamento marxista. Rio de Janeiro: Jorge Zahar, 2001.

FAORO, R. Os Donos do Poder. São Paulo: Editora Globo, 2001.

FAUSTO, B. História concisa do Brasil. São Paulo: Editora da Universidade de São Paulo, Imprensa Oficial do Estado, 2001.

FERREIRA, A. B. H. Novo Dicionário da Língua Portuguesa. Rio de Janeiro: Editora Nova Fronteira, 1986.

IBGE. Enciclopédia dos Municípios Brasileiros. XXXI volume. Rio de Janeiro: 1959. 
MELLO, J. M. C.; NOVAIS, F. A. Capitalismo tardio e sociabilidade moderna. In: SCHWARCZ, Lilia Moritz (org.). História da vida privada no Brasil. São Paulo: Cia. Das Letras, 1998. V. 04.

MOTTA, C. G. Ideologia da Cultura Brasileira (1933-1974). São Paulo: Ática, 1980.

RIBEIRO, M. L. S. História da educação brasileira: a organização escolar. $4^{\mathrm{a}}$ ed. São Paulo: Editora Moraes, 1982.

RODRIGUES, M. A década de 50: populismo e metas desenvolvimentistas no Brasil. São Paulo: Editora Ática, 1992.

SILVA, S. Expansão cafeeira e origens da indústria no Brasil. São Paulo: Alfa-Omega, 1976.

SINGER, P. Evolução da Economia e vinculação internacional. In: SACHAS, Ignacy . Brasil: um século de transformações. São Paulo: Companhia das Letras, 2001.

SKDIMORE, T. De Getúlio a Castelo. Rio de Janeiro: Editora Saga, 1969.

SORJ, B. A nova sociedade brasileira. Rio de Janeiro: Jorge Zahar Editora, 2000.

SODRÉ, N. W. História da imprensa no Brasil. Rio de Janeiro: Graal, 1999.

Tribuna dos Municípios 1954-1959.Casa da Cultura Irati - Pr.

TOLEDO, C. N. ISEB: fábrica de ideologias. São Paulo, SP: Ática, 1982.

VICENTINO, C. História Memória Viva. 2a edição, São Paulo: Editora Scipione, 1994.

XAVIER, M. E. S. P. Capitalismo e escola no Brasil: a constituição do liberalismo em ideologia educacional e as reformas do ensino (1931-1961). Campinas-SP: Papirus, 1990.

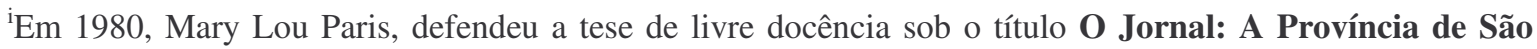
Paulo (1875-1889), na Universidade de São Paulo - Faculdade de Educação. Pela Universidade Federal de Uberlândia, em 1999, Carlos Henrique de Carvalho, defende a dissertação de mestrado com o título Imprensa e Educação: o pensamento educacional do professor Honório Guimarães (Uberabinha MG, 1905-1922). Também pela Universidade Federal de Uberlândia, em 2002, Sirlene de Castro Oliveira, defende a dissertação de mestrado Embates entre o Ensino Religioso e o Ensino Laico na Imprensa de Uberaba, MG (1924-1934). Na tese de doutorado, Imprensa Pedagógica: um estudo de três revistas mineiras destinadas a Professores, Isabel Cristina Alves da Silva Frade, pela Universidade Federal de Minas Gerais, em 2000, analisa a produção mineira de três revistas pedagógicas. Marcília Rosa Periotto em A "espiral do progresso e a felicidade da nação": a instrução do povo para o advento do trabalho livre no Brasil de 1840 a 1850, tese de Doutorado, pela Faculdade de Educação - UNICAMP, em 2001, procura discutir metodologicamente a utilização da imprensa enquanto predominantemente educativa a partir da revista $O$ Progresso.

ii O jornal "Tribuna dos Municípios", de Irati (PR), foi fundado por Antonio Lopes Júnior, em 24 de maio de 1954. Apesar de não ser um jornal específico da área educacional, ou seja, um periódico educacional, este jornal dependente apenas da publicidade local e sem grandes tiragens, traz em cada publicação artigos, notícias e anúncios que tratam do tema.

iii Em 1920, na indústria no Brasil o valor da produção dos bens de consumo era de 85, 4\% em relação a $14,6 \%$ de bens de produção. (SILVA, 1976, p. 113)

Revista HISTEDBR On-line, Campinas, n.34, p.108-126, jun.2009 - ISSN: 1676-2584 125 
iv O termo Patrimonialismo foi largamente empregado nos estudos sobre o Brasil para caracterizar a apropriação dos recursos do Estado, seja pelos políticos ou funcionários públicos, seja por setores privados. (SORJ, 2000, p. 13) Para saber mais sobre o Patrimonialismo ver FAORO, R. Os Donos do Poder. São Paulo: Editora Globo, 2001.

${ }^{v}$ Os textos retirados do jornal foram transcritos na íntegra.

${ }^{v i}$ A Guerra Fria caracterizou-se pela confrontação entre o bloco capitalista, liderado pelos Estados Unidos, e o bloco socialista, liderado pela União Soviética. Logo em seguia à Segunda Guerra Mundial deu-se o progressivo alinhamento dos países aos dois grandes blocos, em meio ao armamentismo e confrontos localizados. (VICENTINO, 1994, p. 194)

${ }^{\text {vii }}$ Para saber mais: SKIDMORE, T. De Getúlio a Castelo. Rio de Janeiro: Editora Saga, 1969.

viii Instrução 113 da SUMOC era um "decreto favorecendo investidores estrangeiros, aos quais, seria permitido importar equipamentos industriais para a produção de bens.” (SKIDMORE, 1969, p. 2002)

Artigo recebido em: 13/3/2009

Aprovado para publicação em 31/08/09 